Louisiana State University

LSU Digital Commons

Faculty Publications

Department of Biological Sciences

8-4-2006

\title{
Crystal Structure of Dps-1, a Functionally Distinct Dps Protein from Deinococcus radiodurans
}

\author{
Song Gun Kim \\ Louisiana State University \\ Gargi Bhattacharyya \\ Louisiana State University \\ Anne Grove \\ Louisiana State University \\ Yong Hwan Lee \\ Louisiana State University
}

Follow this and additional works at: https://digitalcommons.Isu.edu/biosci_pubs

\section{Recommended Citation}

Kim, S., Bhattacharyya, G., Grove, A., \& Lee, Y. (2006). Crystal Structure of Dps-1, a Functionally Distinct Dps Protein from Deinococcus radiodurans. Journal of Molecular Biology, 361 (1), 105-114.

https://doi.org/10.1016/j.jmb.2006.06.010

This Article is brought to you for free and open access by the Department of Biological Sciences at LSU Digital Commons. It has been accepted for inclusion in Faculty Publications by an authorized administrator of LSU Digital Commons. For more information, please contact ir@lsu.edu. 


\section{Crystal Structure of Dps-1, a Functionally Distinct Dps Protein from Deinococcus radiodurans}

\section{Song-Gun Kim, Gargi Bhattacharyya, Anne Grove and Yong-Hwan Lee*}

Department of Biological

Sciences, Louisiana State University, Baton Rouge Louisiana, 70803, USA

\begin{abstract}
DNA protection during starvation (Dps) proteins play an important role in protecting cellular macromolecules from damage by reactive oxygen species (ROS). Unlike most orthologs that protect DNA by a combination of DNA binding and prevention of hydroxyl radical formation by ferroxidation and sequestration of iron, Dps- 1 from the radiation-resistant Deinococcus radiodurans fails to protect DNA from hydroxyl radicalmediated cleavage through a mechanism inferred to involve continuous release of iron from the protein core. To address the structural basis for this unusual release of $\mathrm{Fe}^{2+}$, the crystal structure of D. radiodurans Dps-1 was determined to $2.0 \AA$ resolution. Two of four strong anomalous signals per protein subunit correspond to metal-binding sites within an iron-uptake channel and a ferroxidase site, common features related to the canonical functions of Dps homologs. Similar to Lactobacillus lactis Dps, a metalbinding site is found at the N-terminal region. Unlike other metal sites, this site is located at the base of an N-terminal coil on the outer surface of the dodecameric protein sphere and does not involve symmetric association of protein subunits. Intriguingly, a unique channel-like structure is seen featuring a fourth metal coordination site that results from 3-fold symmetrical association of protein subunits through $\alpha 2$ helices. The presence of this metal-binding site suggests that it may define an iron-exit channel responsible for the continuous release of iron from the protein core. This interpretation is supported by substitution of residues involved in this ion coordination and the observation that the resultant mutant protein exhibits significantly attenuated iron release. Therefore, we propose that $D$. radiodurans Dps-1 has a distinct iron-exit channel.
\end{abstract}

(C) 2006 Elsevier Ltd. All rights reserved.

Keywords: reactive oxygen species; DNA protection; oxidative stress; metal binding standard DNA repair pathways, novel repair pathways, or recombination events facilitated by its ring-like nucleoid. ${ }^{3-8}$ Compared to radiation-sensitive bacteria, $D$. radiodurans has a lower total iron content. ${ }^{9}$ As the ROS $\mathrm{H}_{2} \mathrm{O}_{2}$ undergoes Fenton chemistry in the presence of $\mathrm{Fe}^{2+}$ to generate damaging hydroxyl radicals, the detoxification of $\mathrm{H}_{2} \mathrm{O}_{2}$ and the sequestration of $\mathrm{Fe}^{2+}$ and its oxidation to $\mathrm{Fe}^{3+}$, which cannot participate in the Fenton reaction, is an important mechanism for preventing oxidative damage to macromolecules. The DNAbinding protein Dps (DNA protection during starvation) serves this function.

Identified initially in Escherichia coli, Dps was shown to protect DNA by its ability to chelate ferrous iron, and by its direct association with DNA. ${ }^{10-12}$ Moreover, Dps serves as an important function in compaction of the E. coli nucleoid. ${ }^{13}$ 
During exponential growth, E. coli Dps is upregulated on exposure to $\mathrm{H}_{2} \mathrm{O}_{2}$ by the transcriptional regulator OxyR, and in the stationary phase, it is expressed at high levels via the alternative sigma factor $\sigma^{\mathrm{S}}$ and induces the formation of toroidal assemblies with the genomic DNA. ${ }^{14,15}$

Twelve copies of the Dps monomer form an assembly akin to the spherical shell formed by ferritins. Each of the 24 subunits of ferritin adopts a four-helix bundle conformation with a fifth helix lying at an angle relative to its axis, and each subunit harbors a highly conserved ferroxidase center that mediates oxidation of ferrous iron. Dps subunits adopt a similar structure, but the ferroxidase center lies at the interface between two subunits. ${ }^{16-19}$ Dps oxidizes $\mathrm{Fe}^{2+}$ to $\mathrm{Fe}^{3+}$, and iron is deposited within the protein cavity as a hydrous ferric oxide mineral; direct oxidation of $\mathrm{Fe}^{2+}$ in the mineral core has been shown to proceed faster than ferroxidation at the ferroxidase center. ${ }^{20,21}$ Entry of iron into the Dps cavity is facilitated by a funnel-shaped 3-fold symmetrical channel with negative electrostatic potential pointing toward the inside of the protein shell, a feature shared by ferritin. ${ }^{22}$ Negatively charged amino acid residues are distributed regularly around the channel and intensify the negative electrostatic force toward the cavity of the protein sphere. ${ }^{17-19}$ While iron can be recovered from ferritin in vitro by treatment with reducing agent and chelator or by partial unfolding, 23 in vivo mechanisms of iron recovery from either Dps or ferritin are unknown. The mode of interaction of Dps with DNA is largely unknown. Although it has been shown to involve the $\mathrm{N}$-terminal extensions preceding the ferritin-like fold, ${ }^{17,24}$ the role of the positively charged residues or metal binding remains unclear.

$D$. radiodurans encodes two proteins with homology to E. coli Dps, one of which (Dps-1) was recently shown to bind DNA in both its dimeric and dodecameric forms. ${ }^{25}$ Notably, while dodecameric Dps-1 forms large assemblies with DNA as seen for other Dps homologs, it is functionally distinct because of its inability to afford efficient protection against hydroxyl radical-mediated DNA cleavage, an observation ascribed to the continuous release of iron from the dodecamer. ${ }^{25}$ Whether the released iron is $\mathrm{Fe}^{2+}$ or $\mathrm{Fe}^{3+}$ is unclear. To address its structure/function relationships, the crystal structure of $D$. radiodurans Dps-1 was determined to $2.0 \AA$ resolution. In addition to structural features common to the family members, a novel iron-exit channel and a regulatory N-terminal metal-binding site, which is dissimilar to that of Lactobacillus lactis Dps, are revealed from the $D$. radiodurans Dps-1 structure.

\section{Results and Discussion}

\section{Overall structure}

Dps-1 shares significant sequence homology with other Dps proteins, although the level of identity is modest (Figure 1). For example, without the Nterminal extension, D. radiodurans Dps-1 exhibits 26\% sequence identity with Listeria Dps and 32\% identity with E. coli Dps. ${ }^{17,18}$ The residues involved in assembly of the ferroxidase center, His 83 from one subunit and Asp110 and Glu114 from another, are conserved, consistent with the reported ability of Dps-1 to ferroxidize $\mathrm{Fe}^{2+} .25$

The crystal structure of D. radiodurans Dps-1 was determined to $2.0 \AA$ resolution by a single wavelength anomalous dispersion (SAD) phasing method, ${ }^{26}$ using the four $\mathrm{Co}(\mathrm{II})$ per protein subunit incorporated during crystallization as the anomalous signal source. The crystal structure contains one protein subunit (residues 32-207) in the asymmetric unit and the rest of the Lys-rich $\mathrm{N}$ terminus (residues 1-31) is disordered. The final structure contains $94.4 \%$ of the residues in the most-favored regions in a Ramachandran plot and the rest in the additionally allowed regions.

As shown in Figure 2(a), the overall conformation of monomeric Dps-1 shows the typical fold of the Dps protein family: an N-terminal coil, four long helices ( $\alpha 1$, residues 55-85; $\alpha 2$, residues 91-119; $\alpha 3$, residues 146-174; and $\alpha 4$, residues 177-201), and a stretch with a short helix ( $\alpha 5$, residues 127-133), which connects $\alpha 2$ and $\alpha 3 .{ }^{16-18}$ Dps-1 is superimposable on other homologs with an r.m.s.d. range of 1.8-3.0 $\AA$ for $C^{\alpha}$ values of the bundle of four long helices.

As shown in Figure 2(b), the functional dodecameric superstructure of $D$. radiodurans Dps-1 is assembled through a P23 space group crystal lattice. Like other Dps proteins, the dodecamer contains a hollow sphere with an inner diameter $48 \AA$, which is comparable to those of other homologs; the inner diameters of Listeria Dps and E. coli Dps are $40 \AA$ and $45 \AA$, respectively. The superstructure shows structural characteristics conserved among most Dps proteins, including the 2 -fold ferroxidase site and the funnel-shaped entry gate.

As revealed from an anomalous Fourier map imbedded in Figure 2(a), the Dps-1 structure includes a total of four protein-bound cobalt ions per protein subunit (Co1-4; Figure 2(a)). The resolution of the Dps-1 diffraction data $(2.0 \AA)$ limits accurate measurements of the occupancies of the four metals. However, when the occupancies of all sites are assumed to be 1.0, a routine assumption with data to this resolution, the $B$-factors are 23.36 (site 3), 29.74 (site 2), 29.81 (site 4), and 37.26 (site 1) $\AA^{2}$, respectively. From these $B$-values, which are comparable to those of the coordinating residues, there is no reason to suspect that the actual occupancies are significantly lower than 1.0. In addition to the two metal sites that are highly conserved among Dps proteins, the 2-fold ferroxidase center (Co2) and the Fe(II) entry gates (Co3), ${ }^{16-18} D$. radiodurans Dps-1 contains two additional metal sites, one near the $\mathrm{C}$ terminus (Co4) and the other near the $\mathrm{N}$ terminus (Co1). Co4 associates at the 3fold contact near the $C$ terminus of $\alpha 2$ helices; as discussed below, the association of a metal ion and 


\begin{tabular}{|c|c|c|c|c|c|c|}
\hline & 10 & 20 & 30 & 40 & 50 & 60 \\
\hline D_radi & MTKKSTKSEA & ASKTKKSGVP & ETGAQGVRAG & GADHADAAHL & GTVNNALVNH & HYLEEKEFQT \\
\hline L_inno & & & & & MKT $* * \star I N$ & $\mathrm{~S} * \star \star \star \star * \star * * \mathrm{VD}$ \\
\hline s_suis & & & & & MQSPAEIA & SFSPRPSLAD \\
\hline H_pylo & & & & & & MK \\
\hline E_coli & & & & MSTAKLVK & SKATNLLYTR & NDVSDSEKKA \\
\hline H_sali & & & M & STQKNARATA & GEVEGSDALR & $\mathrm{MDADR} *$ * $\mathrm{AEQ}$ \\
\hline $\mathrm{L}^{-}$lact & & & & MITKLM & IDEKYAKELD & KAEIDHHKPT \\
\hline
\end{tabular}

\begin{tabular}{|c|c|c|c|c|c|c|}
\hline & 70 & 80 & 90 & 100 & 110 & 120 \\
\hline D_radi & VAETLQRNLA & TTISLYLKFK & KYHWDIRGRF & FRDLHLAYDE & FIAEIFPSID & EQAERLVALG \\
\hline L_inno & TKEFLNHQVA & NLNVFTVKIH & QIHWYMRGHN & FFTLHEKMDD & LYSEFGEQMD & EVAERLLAIG \\
\hline S_suis & SKAVLNQAVA & DLSVAHSILH & QVHWYMRGRG & FMIWHPKMDE & YMEEIDGYLD & EMSERLITLG \\
\hline H_pylo & TFEILKHLQA & DAIVLFMKVH & NFHWNVKGTD & FFNVHKATEE & IYEEFADMFD & DLAERIVQLG \\
\hline E_coli & TVELLNRQVI & QFIDLSLITK & QAHWNMRGAN & FIAVHEMLDG & FRTALIDHLD & TMAERAVQLG \\
\hline H_sali & CVDALNADLA & NVYVLYHQLK & KHHWNVEGAE & FRDLHLFLGE & AAETAEEVAD & ELAERVQALG \\
\hline \multirow{3}{*}{ L_lact } & AGAMLGHVLS & NLFIENIRLT & QAGIYAKSP* & **VKCEYLRE & IAQREVEYFF & KISDLLLDEN \\
\hline & $\alpha \alpha, \alpha, \alpha, \alpha 1 \alpha, \alpha \alpha \alpha$ & $\alpha, \alpha, \alpha, \alpha, \alpha, \alpha, \alpha, \alpha, \alpha, \alpha$ & $\alpha, \alpha, \alpha, \alpha, \alpha$ & $\alpha, \alpha, \alpha, \alpha, \alpha, \alpha, \alpha, \alpha, \alpha$ & $\alpha, \alpha, \alpha, \alpha, \alpha, 2 \alpha, \alpha, \alpha, 0$ & $\alpha, \alpha \alpha \alpha, \alpha, \alpha, \alpha, \alpha, \alpha$ \\
\hline & 130 & 139 & 148 & 158 & 168 & 178 \\
\hline D_radi & GSPLAAPADL & ARYST*VQVP & QETV*RDART & QVADLVQDLS & RVGKGYRDDS & QACDEANDPV \\
\hline L_inno & GSPFSTLKEF & LENAS * VEEA & PYTKPKTMDQ & LMEDLVGTLE & LLRDEYKQGI & ELTDKEGDDV \\
\hline S_suis & GAPFSTLKEF & SENSQ * LKEV & LGDYNVTIEE & QLARVVEVFR & YLAALFQKGF & DVSDEEGDSV \\
\hline H_pylo & HHPLVTLSEA & IKLTR*VKEE & TKTS*FHSKD & IFKEILEDYK & YLEKEFKELS & NTAEKEGDKV \\
\hline E_coli & GVALGTTQVI & NSKTP*LKSY & PLDI *HNVQD & HLKELADRYA & IVANDVR * * * & KAIGEAKDDD \\
\hline H_sali & GVPHASPETL & QAEAS*VDVE & DEDV*YDIRT & SLANDMAIYG & DIIEATREHT & ELAENLGDHA \\
\hline \multirow[t]{3}{*}{ L_lact } & EIVPSTTEEF & LKYHKFITED & PKAKYWTDED & LLESFIVDFQ & AQNMFITRAI & KLANKEEKFA \\
\hline & $\alpha \alpha 5 \alpha$ & $\alpha \alpha \alpha$ & $\alpha \alpha \alpha$ & $\alpha \alpha \alpha \alpha \alpha \alpha \alpha \alpha \alpha \alpha \alpha$ & $\alpha \alpha \alpha \alpha 3 \alpha \alpha \alpha \alpha \alpha$ & $\alpha \alpha \alpha \alpha \alpha \alpha$ \\
\hline & 188 & 198 & 207 & & & \\
\hline D_radi & TADMYNGYAA & TIDKIRWMLQ & AIMDDERLD & & & \\
\hline L_inno & TNDMLIAFKA & SIDKHIWMFK & AFLGKAPLE & & & \\
\hline s_suis & TNDIFNVAKA & SIEKHIWMLQ & AELGQAPKL & & & \\
\hline H_pylo & TVTYADDQLA & KLQKS IWMLQ & AHLA & & & \\
\hline E_coli & TADILTAASR & DLDKFLWFIE & CNIE & & & \\
\hline H_sali & TAHMLREGLI & ELEDDAHHIE & HYLEDDTLVT & QGALE & & \\
\hline \multirow[t]{2}{*}{ L_lact } & LAAGVVELYG & YNLQVIRNLA & GDLGKSVADF & HDEDEDNDN & & \\
\hline & $\alpha \alpha, \alpha \alpha \alpha$ & $\alpha \alpha \alpha$ & & & & \\
\hline
\end{tabular}

Figure 1. Dps sequences aligned using the program CLUSTAL W: ${ }^{34}$ D_radi, Dps-1 Deinococcus radiodurans; L_inno, Dps (originally identified as ferritin) Listeria innocua; S_Suis, Dpr Streptococcus suis; H_pylo, HP-NAP Helicobacter pylori; E_coli, Dps Escherichia coli; H_sali, DpsA Halobacterium salinarum; L_lact, DpsB Lactococcus lactis. The $\alpha$-helices of Dps-1 are identified below the alignment, numbered according to the conventional numbering of Dps helices, and colored as in Figure 2(a). The conserved residues at the ferroxidase site according to Listeria Dps are shown in shadow. Residues at the $\mathrm{N}$ terminus and $\alpha 1$ of $D$. radiodurans and L. lactis Dps shown in blue participate in metal coordination at the $\mathrm{N}$ terminus. The red residues in helices $2 \alpha$ and $4 \alpha$ indicate the metal binding site of the iron entry and exit channels, respectively.

other electrostatic properties suggests the existence of a 3-fold exit channel that may be responsible for the continuous release of iron that is characteristic of Dps-1.25 The fourth metal-binding site near the $\mathrm{N}$ terminus (Co1) on the outer surface of the dodecamer does not involve symmetric association of subunits, unlike the other sites.

\section{The conserved ferroxidase center and the entry gate}

Among the four cobalt-binding sites in D. radiodurans Dps-1, Co2 binds to the well-conserved ferroxidase center formed by 2-fold symmetry around the $Y$-axis, using His83 from one monomer, Asp110 and Glu114 from the other monomer, and two water molecules to form an octahedral configuration (Figure 3(a)). There are 12 such sites in dodecameric Dps-1 and the 2-fold symmetryrelated, cobalt-binding ferroxidase sites are $23 \AA$ apart. As suggested by the strict conservation of amino acid residues involved in coordinating metal at the ferroxidase center (with the exception of $L$. lactis Dps, which lacks ferroxidase activity; Figure 1 ), the ferroxidase center of Dps-1 is very similar to those of other homologs, as exemplified by its superposition on that of Listeria Dps (Figure 3(a)). The sequence and structural homology at the ferroxidase center is consistent with the reported ferroxidase activity of Dps-1 and suggests that Dps1 , like other Dps homologs, would prefer $\mathrm{H}_{2} \mathrm{O}_{2}$ to $\mathrm{O}_{2}$ as a substrate. 11,20

As in other Dps family proteins, there are eight 3fold symmetry axes penetrating the dodecameric Dps-1 sphere (Figure 2(b)). Four of these are funnelshaped channels, consisting mainly of negatively charged amino acids, create a negative electrostatic potential gradient, and they have been considered as the iron entry channels. ${ }^{17,18}$ This charge gradient is so strong that escape of ions from the cavity 

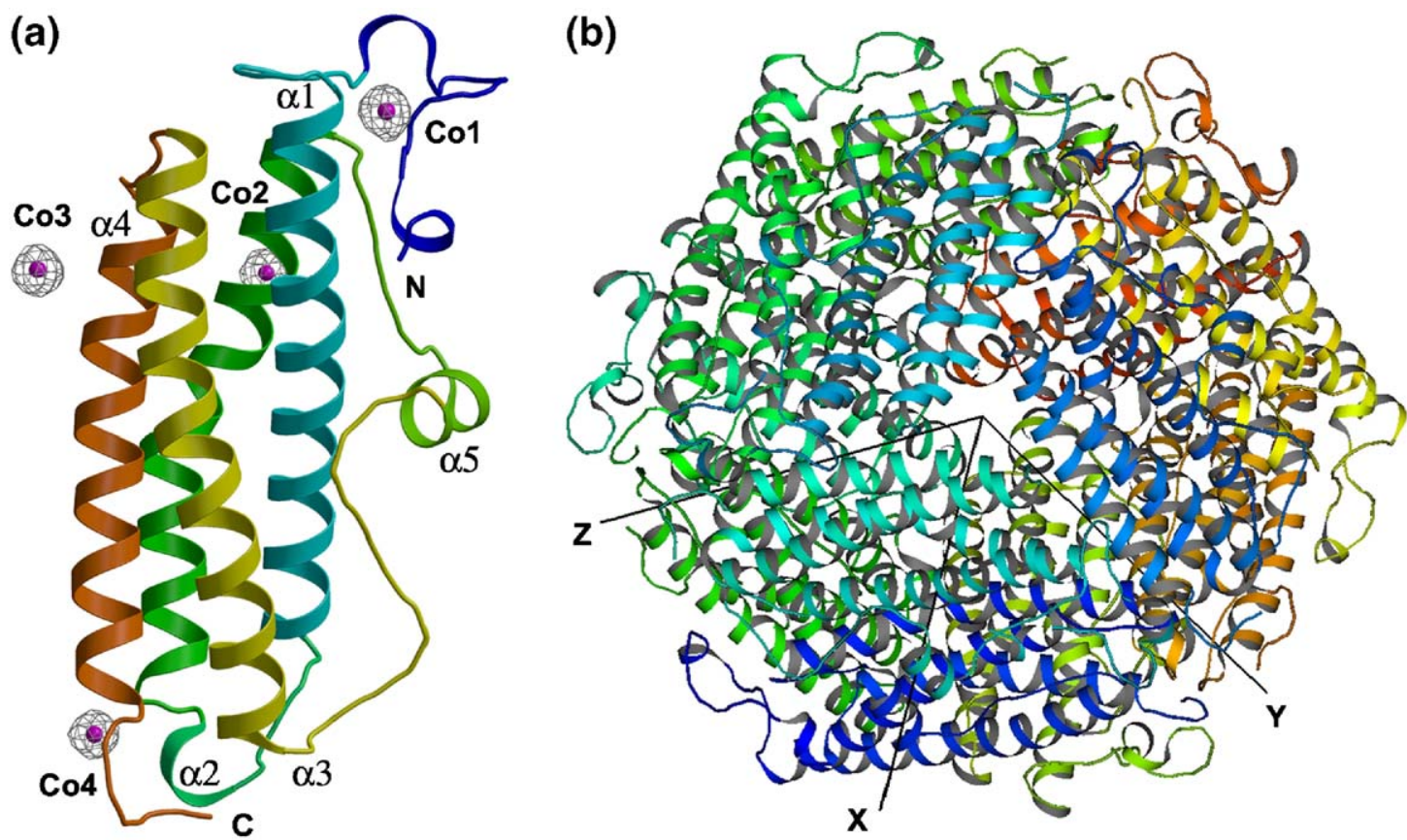

Figure 2. Folding of D. radiodurans Dps-1 and the dodecameric superstructure. (a) Ribbon diagram of monomeric Dps-1 with the four bound Co ions shown as four red balls representing the anomalous difference Fourier map contoured at a level of $5 \sigma .(\mathrm{b})$ The dodecameric superstructure constituted by crystal contacts. Each subunit is shown in a different color and, to show the symmetrical relationship, the three Cartesian axes are presented. Unless mentioned otherwise, all Figures were generated using MOLSCRIPT v2.1. ${ }^{35}$ The density maps are generated using BobScript v.2.6b, ${ }^{36}$ and incorporated using Raster3D V.2.3. ${ }^{37}$

through these channels is unlikely. ${ }^{22}$ Three Asp172 residues form the outer rim of a negative electrostatic environment, three Asn184 residues form the central ring, and the Co3-bound internal rim, consisting of three Asp181 residues, is located at the bottom. These constellations are arranged in such a way that form a channel in which the negative electrostatic potential gradient increases toward the inside of the protein (Figure 3(b)). In E. coli Dps, Asp142, Thr149, and Asp146 are similarly located to play the same role and the Listeria Dps also follows this pattern (Figures 1 and $3(\mathrm{~b})$ ). (a)
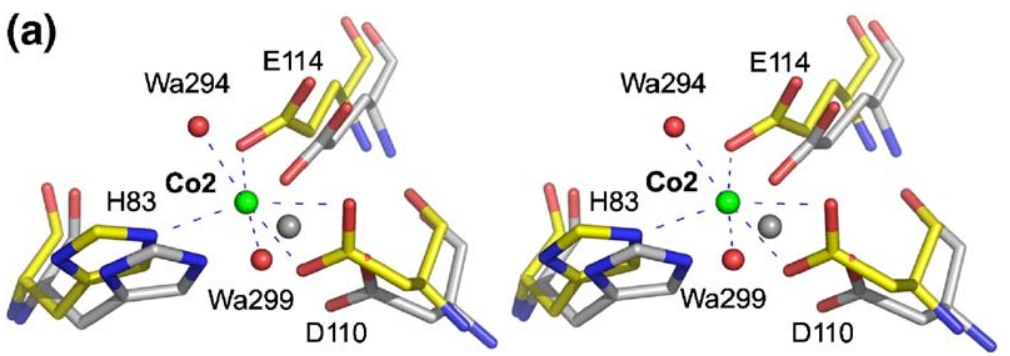

(b)

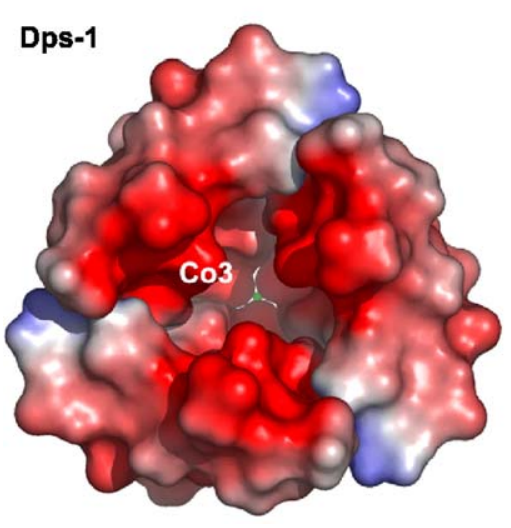

Figure 3. (a) The cobalt (Co2) binding site in Dps-1 in comparison with the ferroxidase site of Listeria Dps. The metal-coordinating amino acid residues of Dps-1 and the two water molecules forming an octahedral coordination of $\mathrm{Co} 2$ are indicated in color: yellow, carbon; red, oxygen; blue, nitrogen; green, cobalt. The amino acid residues and iron of Listeria Dps are represented in gray. (b) Electrostatic potential of the iron entry channels of Dps-1 (left) and E. coli Dps (right). Partial segments from the dodecamers were selected to reconstruct the channels and the electrostatic potential was calculated using APBS, ${ }^{38}$ and drawn using PyMOL v0.99 [http://pymol.sourceforge. net/]. Negative charges are colored red and positive charges are colored blue. 
However, as shown in Figure 3(b), the potential gradients formed and the inner openings are considerably different between the two structures. Dps-1 has an additional negative charge donated by Glu173 that increases the electrostatic gradient, whereas E. coli Dps has no residue serving a similar function. Although E. coli Dps features a conserved Glu138 in this position (Figure 1), this residue does not contribute to formation of the gradient due to structural differences in the outermost rim (Figure 3(b)). While overall shapes of the channels formed at these 3-fold symmetry axes are comparable, the structures differ significantly in detail; for example, the L. lactis Dps homologs contain wider channels than those seen in E. coli or Listeria Dps, and in Dps from Halobacterium salinarum, the funnel is plugged by a row of Glu141, His150, Arg153 and Glu154 residues and is unlikely to function as an iron access route. ${ }^{19}$ We note also that the much slower rate of ferroxidation by $D$. radiodurans Dps- 1 compared to the rates reported for E. coli and Listeria Dps may arise as a consequence of the much narrower internal opening that may retard entry of iron into the protein cavity. ${ }^{25}$

\section{The cobalt binding site at the $\mathrm{N}$-terminal region}

Compared to the three other sites, the Co1 site is coordinated by residues from a single protein subunit and is located at the outer surface of the dodecameric sphere. The tetragonal coordination includes residues from the coiled $\mathrm{N}$ terminus (Asp36, His39, and His50) and the $\alpha 1$ helix (Glu55), as shown in Figure 4(a). A metal-binding site within the N-terminal extension was observed also in L. lactis Dps, where $\mathrm{Zn}^{2+}$ was reported to be coordinated by two histidine residues, His22 and His33, and two water molecules. ${ }^{24}$ In L. lactis Dps, the presence of $\mathrm{Zn}^{2+}$ does not appear to alter the conformation of the N-terminal segment. However, the amino acid sequence in this region shares no homology between Dps homologs.

The two N-terminal metal-binding sites in Dps-1 and L. lactis Dps are compared in Figure 4(b). There is no structural similarity between L. lactis Dps and $D$. radiodurans Dps-1 in this region, and the two sites are $14 \AA$ apart. Previous analysis of E. coli and L. lactis Dps both suggested that the $\mathrm{N}$ termini of each Dps homolog may play an important role in DNA-binding, although the mechanistic details have yet to be addressed. ${ }^{12,24}$ The DNA-binding properties of $D$. radiodurans Dps- 1 are consistent with a role for its $\mathrm{N}$ termini in complex formation. If this hypothesis is correct, then the metal site may serve a regulatory function; binding of a cation to this site could perhaps control the relative orientations of the $\mathrm{N}$ terminus and the main body of the protein.

(a)

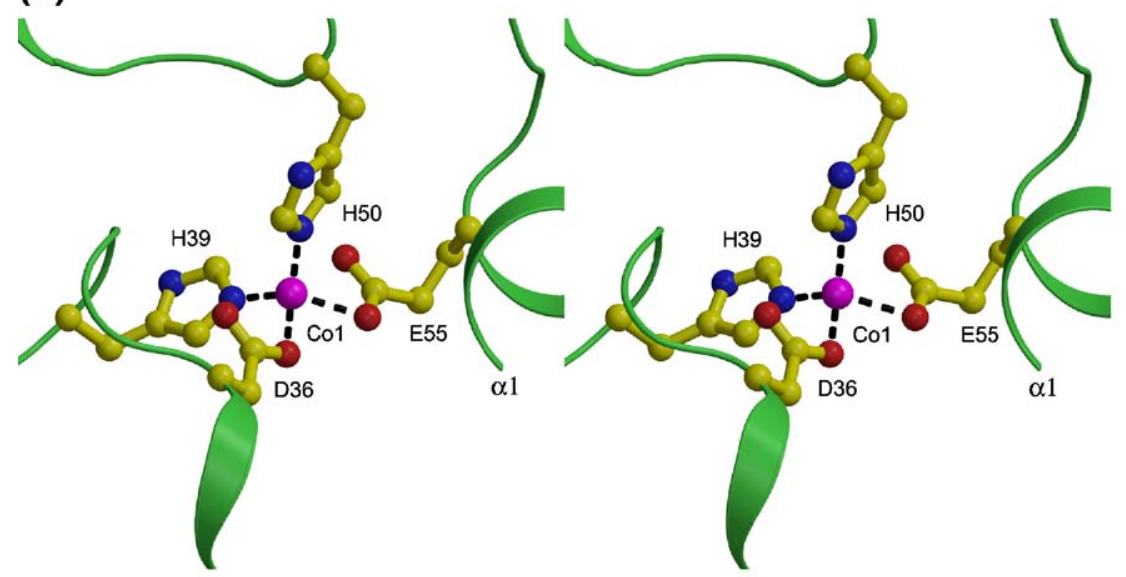

(b)
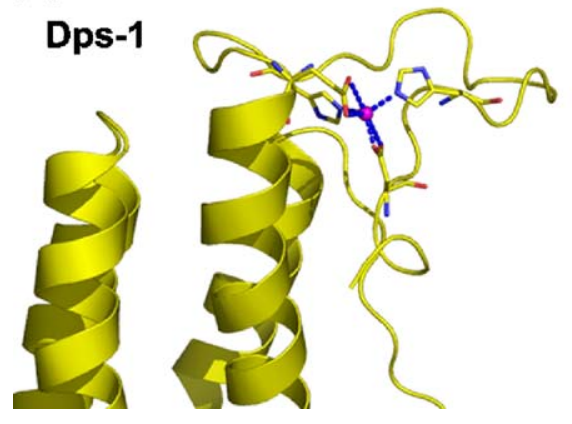

\section{L. lactis}
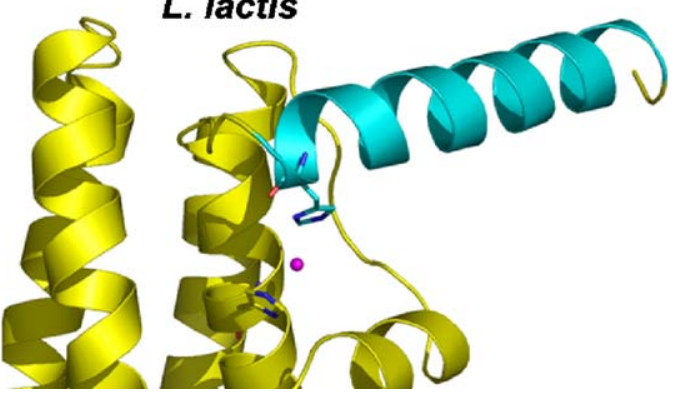

Figure 4. The N-terminal Co-binding site. (a) The site for Co1 located near the $\mathrm{N}$ terminus is shown in stereo. The interactions between the metal ion and the protein residues are depicted with broken lines. (b) Comparison of the metalbinding sites at the N-terminal regions of Dps-1 (left) and L. lactis Dps (right) generated by PyMOL v0.99 [http://pymol. sourceforge.net/]. 


\section{The novel 3-fold channel with bound cobalt}

The fourth metal-binding site is unique to $D$. radiodurans Dps-1 and is found where another 3-fold symmetry axis is generated by residues from the $C$ terminus and the $\alpha 2$ helix. This 3 -fold association constitutes a new funnel-shaped channel, which, in contrast to the iron entry channel, is wider at the interior of the protein shell (Figure 5(a)). In most Dps homologs, the equivalent symmetry axes are closed due to differences in amino acid sequence. However, in H. salinarum Dps, three channels are formed along this symmetry axis and appear to serve as $\mathrm{Fe}^{2+}$ entry gates, while the entry gate otherwise shared among other homologs is closed. ${ }^{19}$

In Dps-1, this channel has a cap at the exit composed of a double layer of 3-fold symmetryrelated Arg205 and Arg89 from each of three subunits, and a sulfate ion is buried between the two Arg layers (Figure 5(a) and (b)). Sulfate is introduced during crystallization and its incorporation in the structure is likely to be a crystallization artifact. Below the Arg-cap, three phenyl rings from Phe90 are arranged to form a hydrophobic tube with a diameter larger than $4.0 \AA$. The hydrophobicity of the phenyl rings may prevent charged molecules from passing through the tube, but there is sufficient space for the rings to rotate and allow movement of an ion with a diameter of $1.5 \AA$. Close to the inner face of the dodecameric sphere, Co4 is tetrahedrally coordinated using 3-fold symmetry-related Asp93 and one water molecule. At the inside of the protein shell, three Glu100 residues form the inner rim of the channel and are stabilized by salt-bridging to Arg92. As mentioned above, this pocket in $H$. salinarum Dps is used as the entry gate and occupied by water and a sodium ion. ${ }^{19}$

Unlike Dps from other species, dodecameric $D$. radiodurans Dps-1 does not protect DNA from $\cdot \mathrm{OH}-$ mediated DNA cleavage. Instead, reactive iron is released continuously and causes a rapid formation of $\cdot \mathrm{OH}$ that results in oxidative degradation of DNA. ${ }^{25}$ The 3 -fold symmetric amino acid arrangement and the structural nature of this cavity cause a steep negative potential gradient, as shown in Figure 5(c), left panel. The outer opening is closed by the two Arg layers due to the buried sulfate (Figure 5(c), right panel); however, negatively charged residues from the $C$ terminus (Asp207) are distributed next to the Arg residues. Thus, without the sulfate, the Arg residues may rotate to interact with the doubly negatively charged $\mathrm{C}$ terminus, leaving the channel open. These circumstances suggest the possibility that the new channel structure is an iron exit gate. The unique concentration of positively charged Arg residues also suggests the possibility that they serve as a contact point with the negatively charged DNA backbone.

\section{Functional test of the exit channel}

To address the possibility that the novel channel structure formed at the 3-fold symmetry axes serves (a)

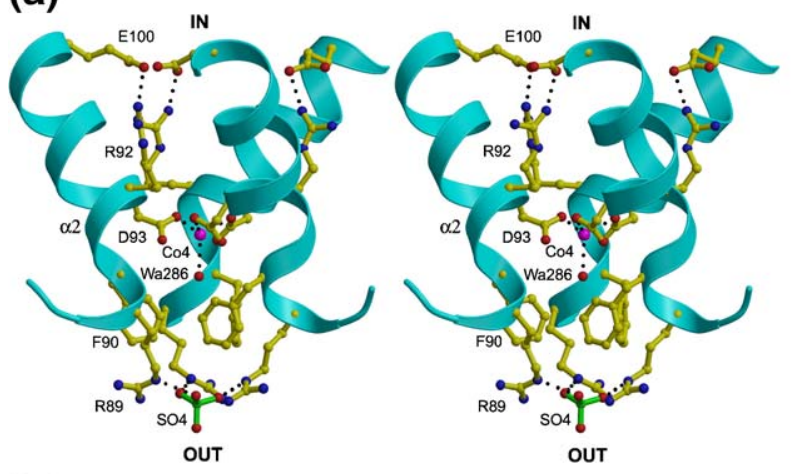

(b)
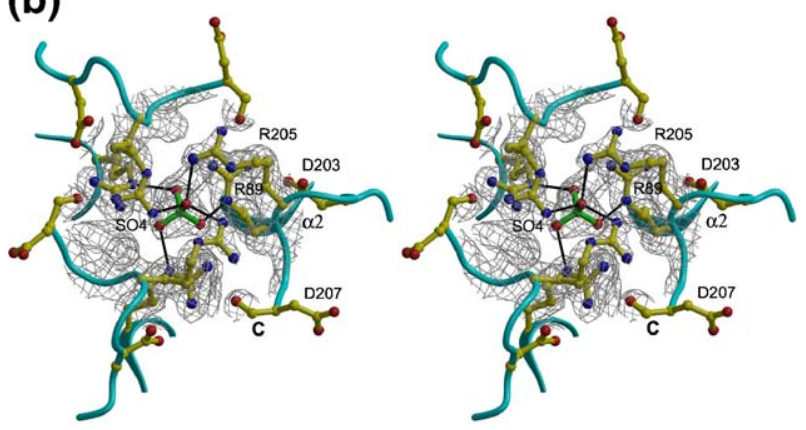

(c)
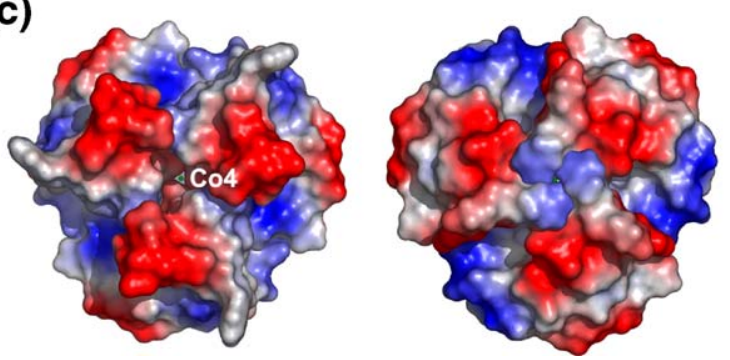

Figure. 5. The Fe(II) exit channel formed by a 3-fold symmetry. (a) The residues involved in formation of the channel are represented in stereo. The 3-fold coordination of Co4 by Asp93 is shown. To indicate the direction of the channel, the luminal side of the dodecamer (entrance) is labeled IN and the exit is labeled OUT. The position of a sulfate ion plugging the channel is shown. (b) The channel-capping Arg residues and the sulfate ion are presented in stereo with a $2\left|F_{\mathrm{o}}\right|-\left|F_{\mathrm{c}}\right|$ electron density map contoured at the $1.1 \sigma$ level. This view is generated by a $90^{\circ}$ rotation of Figure 3(a) around an axis parallel with the plane. (c) The protein surface potentials of the exit gate channel. The channel is viewed from both the inside (left) and the outside (right) of the dodecameric sphere. Bound Co ions are shown as green balls. Partial segments of Dps1 dodecamer were selected to reconstruct the channels, and the electrostatic potential was calculated using $\mathrm{APBS}^{38}$ and drawn using PyMOL v0.99. [http://pymol. sourceforge.net/]. Negative charges are colored red and positive charges are colored blue.

as an iron exit port, substitutions of Arg92 $\rightarrow$ Ile and Asp93 $\rightarrow$ Ala that destroy the coordination of Co4 were performed. Two residues were targeted simultaneously for mutagenesis to ensure disruption of the metal coordination. Residues were substituted according to the corresponding amino 
acid sequence of E. coli Dps (introducing Ile and Ala in place of Arg92 and Asp93, respectively), which is most homologous to D. radiodurans Dps-1, yet unable to sustain the Fenton reaction by release of iron. ${ }^{10}$ The mutant protein, Dps-no-exit, adopts a dodecameric structure, as confirmed by glutaraldehyde-mediated crosslinking, and it is capable of ferroxidation of $\mathrm{Fe}^{2+}$ and the formation of a mineralized iron core, as confirmed by the diagnostic absorbance at 300-400 nm (data not shown). Furthermore, mutant Dps-1 migrates to the same position on native PAGE as wild-type dodecameric Dps-1, previously shown by gel-filtration chromatography to exist quantitatively as a dodecamer in solution (data not shown). These observations indicate that the mutations do not disrupt assembly of the spherical shell.

As shown in Figure 6, partial cleavage of supercoiled DNA with hydroxyl radical leads to formation of a relaxed species (lane 2; note that reaction conditions were selected explicitly not to result in complete DNA degradation). To compare the extent to which Dps-1 and mutant Dps-1-no-exit release iron that may generate DNA-damaging hydroxyl radicals, DNA was incubated with either protein in the absence of added iron. While incubation of supercoiled DNA with Dps-1 containing a mineralized iron core results in some DNA relaxation (lane 5), no DNA cleavage is evident when DNA is incubated with core-containing Dps-1-no-exit (lane 3). Addition of $\mathrm{CaCl}_{2}$ and $\mathrm{H}_{2} \mathrm{O}_{2}$ leads to only modest cleavage of DNA in the presence of Dps-1-no-exit, while more extensive degradation is seen in the

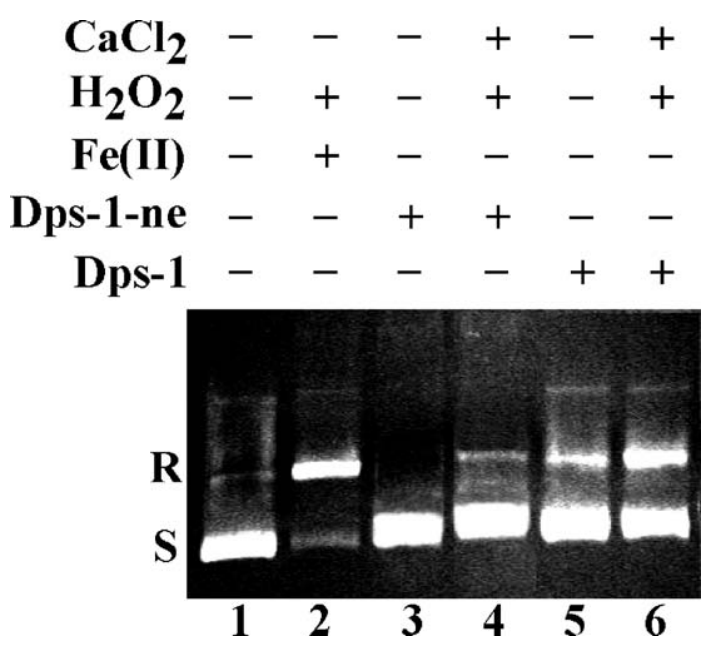

Figure 6. Cleavage of supercoiled DNA by hydroxyl radical in the presence of dodecameric Dps-1 and Dps-1no-exit. Reactions contain $100 \mathrm{ng}$ of supercoiled DNA without protein (lanes 1 and 2), with Dps-1-no-exit (Dps1-ne; lanes 3 and 4) or with Dps-1 (lanes 5 and 6). The reactions in lanes 4 and 6 contain $5 \mathrm{mM} \mathrm{CaCl}_{2}$ and $10 \mathrm{mM} \mathrm{H}_{2} \mathrm{O}_{2}$. The reaction in lane 2 contains $150 \mu \mathrm{M}$ Fe $\left(\mathrm{NH}_{4}\right)_{2}\left(\mathrm{SO}_{4}\right)_{2}$ and $10 \mathrm{mM} \mathrm{H} \mathrm{O}_{2}$. The basis for the inclusion of $\mathrm{Ca}^{2+}$ is its ability to facilitate release of iron from the Dps-1 mineral core under certain circumstances. ${ }^{25}$ Supercoiled (S) and relaxed (R) DNA are identified at the left. presence of wild-type Dps-1 (compare lanes 4 and 6 ). This observation indicates that release of iron from the core is abrogated in Dps-1-no-exit, and supports the hypothesis that the novel channel functions as the iron exit gate in $D$. radiodurans Dps-1. Whether $\mathrm{Fe}^{2+}$ or $\mathrm{Fe}^{3+}$ is released is not known; while $\mathrm{Fe}^{2+}$ would readily cause the generation of toxic hydroxyl radicals through Fenton chemistry, hydroxyl radicals have been shown to form by reactions between $\mathrm{H}_{2} \mathrm{O}_{2}$ and $\mathrm{Fe}^{3+}$, and by mechanisms that are still under investigation. ${ }^{27,28}$

\section{Biological significance}

E. coli Dps is upregulated in response to oxidative stress or starvation by the $\mathrm{H}_{2} \mathrm{O}_{2}$-sensitive transcriptional regulator OxyR or by the alternative sigma factor $\sigma^{S}$ and, as a result, the genome adopts a toroidal structure. ${ }^{14,15}$ It is therefore tempting to speculate that $D$. radiodurans Dps- 1 may contribute to maintenance of the toroidal genome structure that is characteristic of this organism, even during exponential growth. ${ }^{7,29}$ In Dps-1, the N-terminal extension, which is considered the DNA-binding domain on the basis of the analysis of other Dps proteins, is longer than in other homologs, consistent with the observed high-affinity DNA binding. ${ }^{25}$ Notably, the structure reveals a unique metalbinding site within the $\mathrm{N}$-terminal region that may predispose its orientation relative to the dodecameric shell and thereby regulate association with DNA. As D. radiodurans has been shown to accumulate relatively high concentrations of $\mathrm{Mn}^{2+}$, it is conceivable that this ion serves to coordinate the N-terminal extensions in vivo. ${ }^{9}$

Perhaps the most unexpected feature of dodecameric Dps-1 is its failure to protect DNA from -OH-mediated degradation, which is otherwise a characteristic shared by all other Dps proteins, regardless of their ability to associate stably with DNA. Such protection is thought to occur as Dps proteins efficiently oxidize $\mathrm{Fe}^{2+}$ to $\mathrm{Fe}^{3+}$ which cannot participate in the Fenton reaction. While Dps-1 has ferroxidation activity in the presence of molecular oxygen, the rates are appreciably slower than those for other homologs, although the ferroxidation profile for Dps-1 is consistent with more rapid surface ferroxidation at the mineral core compared to the ferroxidase center, as seen for other homologs. $20,21,25$ Secondly, release of iron from dodecameric Dps-1 was suggested to contribute to the observed lack of protection from ${ }^{\circ} \mathrm{OH}$-mediated DNA cleavage; notably, dimeric Dps-1 does protect DNA from ${ }^{\circ} \mathrm{OH}$-mediated DNA cleavage, consistent with the interpretation that it is iron stored within the mineral core that is released to participate in the generation of hydroxyl radicals. ${ }^{25}$ We cannot determine whether the metal sites on the protein surface are occupied with iron, or indeed if other metal ions may be bound preferentially. Since release of iron, as measured by DNA damage, is not observed for dimeric Dps-1, release of iron from surface sites is unlikely, as we have no reason to suspect that 
surface sites are occupied differentially in dimeric or dodecameric Dps-1. Similarly, the fact that mutant Dps-1 exhibits different rates of DNA degradation argues against release of iron from surface sites. The structure of Dps-1 offers a mechanistic explanation for these observations; unlike other Dps homologs, a second channel is observed in addition to the ironentry pore that is shared among most homologs, a notable exception being $H$. salinarum $\mathrm{DpsA}$, in which the canonical iron entry channel is closed and the alternative channel appears to serve as the entry gate, as discussed above. ${ }^{19}$ In Dps-1, this second channel appears to serve as an exit port, allowing the facile release of iron, perhaps in response to charge differentials between the interior and exterior of the protein shell.

One of the remaining questions is whether $\mathrm{Fe}^{3+}$ or $\mathrm{Fe}^{2+}$ is released from the Dps- 1 dodecamer. Our data do not provide an answer to this question, nor does the current structure suggest an additional redox catalytic site, which might be required to reduce core $\mathrm{Fe}^{3+}$ if $\mathrm{Fe}^{2+}$ is released. It is possible that a reduction occurs near the event of release lest the protein should be damaged by reactive $\mathrm{Fe}^{2+}$ and/or $\mathrm{Fe}^{2+}$ should undergo futile cycles of reduction and oxidation inside the protein shell. Together with this rationale, we note the unusual coordination of Co4 in which a total of seven oxygen atoms are located within a distance of $2.5 \AA$ (Figure 5(a)). This site, whose structural characteristics provide no ion selectivity, could perhaps be occupied by $\mathrm{Mn}^{2+}$, which is uniquely abundant in $D$. radiodurans and could readily reduce exiting $\mathrm{Fe}^{3+}$ to $\mathrm{Fe}^{2+}$ in vivo. These features are unique to Dps-1 and cannot be generalized to other Dps proteins.

In ferritin, dioxygen is used to concentrate iron for use in iron cofactors involved in respiration, photosynthesis or nitrogen fixation. In contrast, bacterial Dps proteins use iron to detoxify dioxygen or peroxide to protect DNA from damage, and Dps proteins are upregulated in response to oxidative stress during exponential growth. Efficient detoxification of $\mathrm{H}_{2} \mathrm{O}_{2}$ occurs by its reaction with $\mathrm{Fe}^{2+}$ within the ferroxidase center, as $\mathrm{H}_{2} \mathrm{O}_{2}$ replaces molecular oxygen as a more efficient oxidant. $D$. radiodurans, compared to radiation-sensitive bacteria, accumulates very low concentrations of intracellular iron, yet it must respond to accumulation of damaging ROS, arising as a result of either metabolic changes or irradiation, by their rapid inactivation. Dps proteins bind two ferrous iron ions at the ferroxidase center for use as cofactors in the essentially concerted two-electron reduction of $\mathrm{H}_{2} \mathrm{O}_{2}$ to $\mathrm{H}_{2} \mathrm{O}$, preventing the toxic one-electron transfer to yield hydroxyl radicals. This function might be compromised in the absence of iron, resulting in the potential accumulation of damaging ROS. The slow ferroxidation of $\mathrm{Fe}^{2+}$ by molecular oxygen combined with facilitated recycling of iron through its facile release from Dps-1 may serve as a homeostatic mechanism to generate an available supply of $\mathrm{Fe}^{2+}$ required for rapid detoxification of ROS or other cellular functions.

\section{Materials and Methods}

\section{Generation of Dps-1 mutant and protein purification}

To introduce Arg92 $\rightarrow$ Ile and Asp93 $\rightarrow$ Ala substitutions into Dps-1, mutagenic PCR was performed by wholeplasmid amplification of a plasmid bearing the Dps-1 gene and forward primer:

\section{5'-GGGGCCGCTTCTTCATTGCCCTG-3'}

designed to introduce the desired mutations (codons underlined) and reverse primer:

\section{5'-GGATGTCCCAGTGGTACTTCTTG-3'}

Mutant Dps-1 (Dps-1-no-exit) was expressed in E. coli BL21(DE3)pLysS with $1.0 \mathrm{mM}$ isopropyl- $\beta$, d-thiogalactopyranoside (IPTG) and purified to homogeneity using heparin agarose chromatography, as described. ${ }^{25}$ Wildtype Dps-1 was expressed in E. coli BL21(DE3) using $0.3 \mathrm{mM}$ IPTG and purified by heparin agarose chromatography ${ }^{25}$ and monoQ anion-exchange chromatography, when required.

\section{Crosslinking, and crystallization of proteins}

Proteins were crosslinked in a total volume of $10 \mu \mathrm{l}$ of $10 \mathrm{mM}$ bicine $(\mathrm{pH} 8.5), 500 \mathrm{mM} \mathrm{NaCl}, 0.1 \%$ (v/v) glutaraldehyde at room temperature for $30 \mathrm{~min}$. Reactions were terminated by addition of an equal volume of Laemmli sample buffer, and the crosslinked products were analyzed by SDS-PAGE.

The crystals were grown at $293 \mathrm{~K}$ by sitting-drop, vapor-diffusion of $8 \mathrm{mg} \mathrm{ml}^{-1}$ protein in $20 \mathrm{mM}$ Tris$\mathrm{HCl}(\mathrm{pH}$ 7.5), $0.5 \mathrm{mM}$ EDTA, 5 mM $\beta$-mercaptoethanol, $5 \%(\mathrm{v} / \mathrm{v})$ glycerol mixed 1:1 $(\mathrm{v} / \mathrm{v})$ with a mother liquor of $100 \mathrm{mM}$ morpholinoethanesulfonic acid (Mes)-NaOH ( $\mathrm{pH}$ 6.5), $100 \mathrm{mM} \mathrm{CoCl}$, $1.8-2.2 \mathrm{M}$ ammonium sulfate. Crystals grew to a size of $0.3 \mathrm{~mm} \times 0.3 \mathrm{~mm} \times 0.3 \mathrm{~mm}$ in two to four weeks.

\section{Iron incorporation and DNA protection assay}

Iron incorporation was measured spectrophotometrically using an Agilent 8453 spectrophotometer. ${ }^{25}$ Ironloaded dodecameric Dps-1 and Dps-1-no-exit were prepared by incubation of $0.4 \mathrm{mg} \mathrm{ml}^{-1}$ of apo-protein with $90 \mu \mathrm{M}$ ferrous ammonium sulfate for $1 \mathrm{~h}$, followed by purification by gel-filtration using Bio-spin 6 columns (BioRad). Introduction of an iron core was confirmed by absorbance spectra showing the characteristic absorbance at $300-400 \mathrm{~nm}^{25}$

Protection of DNA from oxidative damage was measured by mixing $100 \mathrm{ng}$ of supercoiled pGEM5 plasmid with 4.3 pmol of iron-loaded dodecameric protein (sufficient to saturate the DNA) in $10 \mu \mathrm{l}$ of $25 \mathrm{mM}$ Tris- $\mathrm{HCl}$ (pH 8.0), $200 \mathrm{mM} \mathrm{NaCl}$ for $10 \mathrm{~min}$ in the presence or in the absence of $5 \mathrm{mM} \mathrm{CaCl}_{2}$. Where indicated, $\mathrm{Fe}\left(\mathrm{NH}_{4}\right)_{2}\left(\mathrm{SO}_{4}\right)_{2}$ and $\mathrm{H}_{2} \mathrm{O}_{2}$ were added at a final concentration of $150 \mu \mathrm{M}$ and $10 \mathrm{mM}$, respectively, and the release of iron was allowed to proceed at room temperature for $20 \mathrm{~min}$. Reactions were terminated with $2 \%$ glycerol, $0.7 \%(\mathrm{w} / \mathrm{v})$ SDS, and the entire reaction was loaded onto a $1 \%(\mathrm{w} / \mathrm{v})$ agarose gel in $0.5 \times$ TBE $(45 \mathrm{mM}$ Tris-borate $(\mathrm{pH} 8.3), 1 \mathrm{mM}$ 
Table 1. Statistics of reflection data and structure refinements

\begin{tabular}{lc}
\hline Space group & $P 23$ \\
Unit cell dimensions $a=b=c(\AA)$ & 90.13 \\
Resolution range $(\AA)$ & $-2.0(2.09-2.0)$ \\
Reflections $(F \geq \sigma(F))$ & 16,815 \\
Redundancy & $9.2(8.4)$ \\
Completeness $(\%)$ & $96.5(90.3)$ \\
$I / \sigma(I)$ & $14.7(1.9)$ \\
$R_{\text {sym }}$ & $0.110(0.48)$ \\
$R_{\text {cryst }}$ & 0.195 \\
$R_{\text {free }}$ & 0.220 \\
No. amino acid residues & 176 \\
No. protein atoms & 1407 \\
No. hetero atoms & 9 \\
No. water molecules & 115 \\
r.m.s.d. from ideal & \\
Bond lengths $(\AA)$ & 0.007 \\
Bond angles $(d e g)$. & 1.1 \\
Dihedral angles $($ deg.) & 19.6 \\
Mean $B$-factor & \\
Protein atom $\left(\AA^{2}\right)$ & 21.2 \\
Hetero atoms $\left(\AA^{2}\right)$ & 29.6 \\
Water atoms $\left(\AA^{2}\right)$ & 30.9 \\
\hline
\end{tabular}

Numbers in parentheses are values in the highest resolution shell. $R_{\text {sym }}=\sum_{h}\left(\sum_{j}\left|I_{h, j}-<I_{h}>\right| / \sum I_{h, j}\right)$, where $h=$ the set of Miller indices, $j=$ the set of observations of reflection $h$, and $\left\langle I_{h}\right\rangle=$ the mean intensity. $R_{\text {cryst }}=\sum_{h}\left\|F_{\mathrm{o}, h}|-| F_{\mathrm{c}, h}\right\| / \sum_{h}\left|F_{\mathrm{o}, h}\right| . R_{\text {free }}$ was calculated using $10 \%$ of the complete data set that was excluded from the refinement.

EDTA). Gels were stained with ethidium bromide after electrophoresis.

\section{X-ray data collection and SAD phasing}

X-ray diffraction data were collected at $100 \mathrm{~K}$ onto a Mar345 image plate detector mounted on an Enraf-Nonius FR591 rotating anode generator. A sweep of $78^{\circ}$ data collection was made with a $1^{\circ}$ oscillation per frame. Data were indexed using DENZO, and merged and scaled using SCALEPACK ${ }^{30}$ Crystals belong to a primitive cubic space group of $P 23$ with unit cell dimensions of $a=b=c=90.13 \AA$ and the asymmetric unit contains one subunit of Dps-1. The reduced data were formatted for the program suites of CCP4 $4^{31}$ and $C N S,{ }^{32}$ and $10 \%$ of the data were marked for free $R$-factor measurements in subsequent structure refinements.

The structure of Dps-1 was determined by a SAD method. Although the diffraction data was collected at a wavelength of $1.5418 \AA$ from a rotating copper anode, the energy level is close to the cobalt $\mathrm{K}$ absorption edge and provided anomalous signals $\left(3.56 \mathrm{e}^{-}\right)$sufficient for SAD. All procedures of SAD phasing were carried out in the CNS phasing suite. Four Co peaks $(>5 \sigma)$ were found from an anomalous Patterson map and their coordinates calculated from real space simulations. The SAD phases were calculated initially using the four cobalt sites $(\mathrm{FOM}=0.27)$ and improved by density modification with the option of solvent flipping implemented in CNS. The improved phases were of sufficient quality to generate a Fourier synthesis map in which unbroken electron densities of four long helices were revealed. Along these helical densities, 64 Ala were built in as the partial structure, and subsequent phase recombination and density modifications generated a map with which initial model building was completed. The initial model went through iterated cycles of manual model rebuilding using $\mathrm{O}^{33}$ and refinement at $2.0 \AA$ using CNS. When $R_{\text {cryst }} / R_{\text {free }}$ reached $0.26 / 0.28$ or below, the four cobalt ions were built into the model, referring to the anomalous Fourier map. As summarized in Table 1 , the final model has $R_{\text {free }} / R_{\text {cryst }}$ of $0.222 / 0.191$ using a total of 1531 scatterers, including solvent molecules, against all available 16,815 reflections in the resolution range of 30.0-2.0 $\AA$. The structure contains a total of 176 residues of the full-length 207 residue protein, with the N-terminal 31 residues appearing disordered.

\section{Protein Data Bank accession code}

The atomic coordinates and structure factors of $D$. radiodurans Dps-1 (code 2F7N) have been deposited in the RCSB Protein Data Bank, Rutgers University, New Brunswick, NJ†.

\section{Acknowledgements}

This work was funded by the National Science Foundation (MCB-0414875 to A.G.) and the Louisiana State Governor's Biotechnology Initiative Fund (to Y.-H.L.). We thank Dr Marcia Newcomer for helpful comments on the manuscripts and for the use of her spectrophotometer.

\section{References}

1. Mattimore, V. \& Battista, J. R. (1996). Radioresistance of Deinococcus radiodurans: Functions necessary to survive ionizing radiation are also necessary to survive prolonged desiccation. J. Bacteriol. 178, 633-637.

2. Battista, J. R. (1997). Against all odds: the survival strategies of Deinococcus radiodurans. Annu. Rev. Microbiol. 51, 203-224.

3. Makarova, K. S., Aravind, L., Wolf, Y. I., Tatusov, R. L., Minton, K. W., Koonin, E. V. \& Daly, M. J. (2001). Genome of the extremely radiation-resistant bacterium Deinococcus radiodurans viewed from the perspective of comparative genomics. Microbiol. Mol. Biol. Rev. 65, 44-79.

4. Daly, M. J., Ouyang, L., Fuchs, P. \& Minton, K. W. (1994). In vivo damage and recA-dependent repair of plasmid and chromosomal DNA in the radiationresistant bacterium Deinococcus radiodurans. J. Bacteriol. 176, 3508-3517.

5. Daly, M. J. \& Minton, K. W. (1996). An alternative pathway of recombination of chromosomal fragments precedes recA-dependent recombination in the radioresistant bacterium Deinococcus radiodurans. J. Bacteriol. 178, 4461-4471.

6. Liu, Y., Zhou, J., Omelchenko, M. V., Beliaev, A. S., Venkateswaran, A., Stair, J. et al. (2003). Transcriptome dynamics of Deinococcus radiodurans recovering from ionizing radiation. Proc. Natl Acad. Sci. USA, 100, 4191-4196.

7. Levin-Zaidman, S., Englander, J., Shimoni, E., Sharma, A. K., Minton, K. W. \& Minsky, A. (2003). Ringlike structure of the Deinococcus radiodurans genome: a key to radioresistance? Science, 299, 254-256.

8. Tanaka, M., Earl, A. M., Howell, H. A., Park, M.-J., Eisen, J. A., Peterson, S. N. \& Battista, J. R. (2004). Analysis of Deinococcus radiodurans's transcriptional

$\dagger$ http://www.rcsb.org 
response to ionizing radiation and desiccation reveals novel proteins that contribute to extreme radioresistance. Genetics, 168, 21-33.

9. Daly, M. J., Gaidamakova, E. K., Matrosova, V. Y., Vasilenko, A., Zhai, M., Venkateswaran, A. et al. (2004). Accumulation of $\mathrm{Mn}(\mathrm{II})$ in Deinococcus radiodurans facilitates gamma-radiation resistance. Science, 306, 1025-1028.

10. Almirón, M., Link, A. J., Furlong, D. \& Kolter, R. (1992). A novel DNA-binding protein with regulatory and protective roles in starved Escherichia coli. Genes Dev. 6, 2646-2654.

11. Zhao, G., Ceci, P., Ilari, A., Giangiacomo, L., Laue, T. M., Chiancone, E. \& Chasteen, N. D. (2002). Iron and hydrogen peroxide detoxification properties of DNA-binding protein from starved cells. A ferritinlike DNA-binding protein of Escherichia coli. J. Biol. Chem. 277, 27689-27696.

12. Ilari, A., Ceci, P., Ferrari, D., Rossi, G. L. \& Chiancone, E. (2002). Iron incorporation into Escherichia coli Dps gives rise to a ferritin-like microcrystalline core. J. Biol. Chem. 277, 37619-37623.

13. Kim, J., Yoshimura, S. H., Hizume, K., Ohniwa, R. L., Ishihama, A. \& Takeyasu, K. (2004). Fundamental structural units of the Escherichia coli nucleoid revealed by atomic force microscopy. Nucl. Acids Res. 32, 1982-1992.

14. Altuvia, S., Almirón, M., Huisman, G., Kolter, R. \& Storz, G. (1994). The dps promoter is activated by OxyR during growth and by IHF and sigma $S$ in stationary phase. Mol. Microbiol. 13, 265-272.

15. Frenkiel-Krispin, D., Ben-Avraham, I., Englander, J. Shimoni, E., Wolf, S. G. \& Minsky, A. (2004). Nucleoid restructuring in stationary-state bacteria. Mol. Microbiol. 51, 395-405.

16. Hempstead, P. D., Yewdall, S. J., Fernie, A. R., Lawson, D. M., Artymiuk, P. J., Rice, D. W. et al. (1997). Comparison of the three-dimensional structures of recombinant human $\mathrm{H}$ and horse $\mathrm{L}$ ferritins at high resolution. J. Mol. Biol. 268, 424-448.

17. Grant, R. A., Filman, D. J., Finkel, S. E., Kolter, R. \& Hogle, J. M. (1998). The crystal structure of Dps, a ferritin homolog that binds and protects DNA. Nature Struct. Biol. 5, 294-303.

18. Ilari, A., Stefanini, S., Chiancone, E. \& Tsernoglou, D. (2000). The dodecameric ferritin from Listeria innocua contains a novel intersubunit iron-binding site. Nature Struct. Biol. 7, 38-43.

19. Zeth, K., Offermann, S., Essen, L.-O. \& Oesterhelt, D. (2004). Iron-oxo clusters biomineralizing on protein surfaces: Structural analysis of Halobacterium salinarum DpsA in its low- and high-iron states. Proc. Natl Acad. Sci. USA, 101, 13780-13785.

20. Yang, X., Chiancone, E., Stefanini, S., Ilari, A. \& Chasteen, N. D. (2000). Iron oxidation and hydrolysis reactions of a novel ferritin from Listeria innocua. Biochem. J. 349, 783-786.

21. Chasteen, N. D. \& Harrison, P. M. (1999). Mineralization in ferritin: an efficient means of iron storage. J. Struct. Biol. 126, 182-194.

22. Takahashi, T. \& Kuyucak, S. (2003). Functional properties of threefold and fourfold channels in ferritin deduced from electrostatic calculations. Biophys. J. 84, 2256-2263.

23. Liu, X., Jin, W. \& Theil, E. C. (2003). Opening protein pores with chaotropes enhances Fe reduction and chelation of Fe from the ferritin biomineral. Proc. Natl Acad. Sci. USA, 100, 3653-3658.

24. Stillman, T. J., Upadhyay, M., Norte, V. A., Sedelnikova, S. E., Carradus, M., Tzokov, S. et al. (2005). The crystal structures of Lactococcus lactis MG1363 Dps proteins reveal the presence of an N-terminal helix that is required for DNA binding. Mol. Microbiol. 57, 1101-1112.

25. Grove, A. \& Wilkinson, S. P. (2005). Differential DNA binding and protection by dimeric and dodecameric forms of the ferritin homolog Dps from Deinococcus radiodurans. J. Mol. Biol. 347, 495-508.

26. Brodersen, D. E., de La Fortelle, E., Vonrhein, C., Bricogne, G., Nyborg, J. \& Kjeldgaard, M. (2000). Applications of single-wavelength anomalous dispersion at high and atomic resolution. Acta Crystallog. sect. $D, 56,431-441$.

27. Perez-Benito, J. F. (2004). Iron(III)-hydrogen peroxide reaction: Kinetic evidence of a hydroxyl-mediated chain mechanism. J. Phys. Chem. A, 108, 4853-4858.

28. Zhao, G., Arosio, P. \& Chasteen, N. D. (2006). Iron(II) and hydrogen peroxide detoxification by human $\mathrm{H}-$ chain ferritin. An EPR spin-trapping study. Biochemistry, 45, 3429-3436.

29. Zimmerman, J. M. \& Battista, J. R. (2005). A ring-like nucleoid is not necessary for radioresistance in the Deinococcaceae. BMC Microbiol. 31, 17-26.

30. Otwinowski, Z. \& Minor, W. (1997). Processing of Xray diffraction data collected in oscillation mode. Methods Enzymol. 276, 307-326.

31. Collaborative Computational Project Number 4. (1994). The CCP4 suite: programs for protein crystallography. Acta Crystallog. sect. D, 50, 760-763.

32. Brünger, A. T., Adams, P. D., M., C. G., DeLano, W. L., Gros, P., Grosse-Kunstleve, R. W. et al. (1998). Crystallography \& NMR System: A new software suite for macromolecular structure determination. Acta Crystallog. sect. D, 54, 905-921.

33. Jones, T. A., Zou, J. Y., Cowan, S. W. \& Kjeldgaard, M. (1991). Improved methods for building protein models in electron density maps and the location of errors in these models. Acta Crystallog. sect. A, 47, 110-119.

34. Thompson, J. D., Higgins, D. G. \& Gibson, T. J. (1994). CLUSTAL W: improving the sensitivity of progressive multiple sequence alignment through sequence weighting, positions-specific gap penalties and weight matrix choice. Nucl. Acids Res. 22, 4673-4680.

35. Kraulis, P. J. (1991). MOLSCRIPT: a program to produce both detailed and schematic plots of protein structures. J. Appl. Crystallog. 24, 946-950.

36. Esnouf, R. M. (1999). Further additions to MolScript version 1.4, including reading and contouring of electron-density maps. Acta Crystallog. sect. D, 55, 938-940.

37. Merritt, E. A. \& Bacon, D. J. (1997). Raster3D: photorealistic molecular graphics. Methods Enzymol. 277, 505-524.

38. Baker, N. A., Sept, D., Joseph, S., Holst, M. J. \& McCammon, J. A. (2001). Electrostatics of nanosystems: application to microtubules and the ribosome. Proc. Natl Acad. Sci. USA, 98, 10037-10041. 